\title{
Vulvovaginal candidiasis: species distribution of Candida and their antifungal susceptibility pattern
}

Adane Bitew ${ }^{1 *}$ (D) and Yeshiwork Abebaw ${ }^{2}$

\begin{abstract}
Background: Vulvovaginal candidiasis is a global issue of concern due to its association with economic costs, sexually transmitted infections, and ascending genital tract infection. The aim of this study was to determine species distribution and antifungal susceptibility pattern of Candida species causing vulvovaginal candidiasis.

Methods: A cross sectional study was conducted from November 2015 to December 2016 at the Family Guidance Association of Ethiopia. Vaginal swabs collected from study subjects that were clinically diagnosed with vulvovaginal candidiasis were cultured. Yeast identification and antifungal susceptibility testing were determined by the automated VITEK 2 compact system. The association of vulvovaginal candidiasis with possible risk factors was assessed and analyzed using SPSS version 20.
\end{abstract}

Results: The overall prevalence of vulvovaginal candidiasis was $41.4 \%$. The association of vulvovaginal candidiasis was statistically significant with previous genital tract infection $(p=0.004)$, number of life-time male sex partners ( $p=.037)$, and number of male sex partners in 12 month $(p=0.001)$. Of 87 Candida isolates recovered, $58.6 \%$ were C. albicans while $41.4 \%$ were non-albicans Candida species. The highest overall drug resistance rate of Candida species was observed against fluconazole (17.2\%), followed by flycytosine (5.7\%). All Candida isolates were 100\% susceptible to voriconazole, caspofungin, and micafungin. C. albicans, was $100 \%$ susceptible to all drugs tested except fluconazole and flycytosine with a resistance rate of 2\% each drug. C. krusei, was 100 and 33.3\% resistant to fluconazole and flycytosine, respectively.

Conclusions: High prevalence rate of vulvovaginal candidiasis and observation of high prevalence rate of nonalbicans Candida species in the present study substantiate, the importance of conducting continuous epidemiological surveys to measure changes in species distribution from C. albicans to non-albicans Candida species in Ethiopia. Although, fluconazole still appeared to be active against all isolates of C. albicans and non-albicans Candida species high resistance rate of $C$. krusei against the drug may demonstrate a search for alternative antifungal drugs when treating vulvovaginal candidiasis caused by C. krusei.

Keywords: Vulvovaginal candidiasis, Non-albicans Candida species antifungal drugs, Ethiopia

\footnotetext{
* Correspondence: Adane.Bitew81@gmail.com

${ }^{1}$ Department of Medical Laboratory Sciences, College of Health Sciences,

Addis Ababa University, P.O. Box1176, Addis Ababa, Ethiopia

Full list of author information is available at the end of the article
}

(C) The Author(s). 2018 Open Access This article is distributed under the terms of the Creative Commons Attribution 4.0 International License (http://creativecommons.org/licenses/by/4.0/), which permits unrestricted use, distribution, and reproduction in any medium, provided you give appropriate credit to the original author(s) and the source, provide a link to the Creative Commons license, and indicate if changes were made. The Creative Commons Public Domain Dedication waiver (http://creativecommons.org/publicdomain/zero/1.0/) applies to the data made available in this article, unless otherwise stated. 


\section{Background}

Vulvovaginal candidiasis here is defined as isolation of Candida species in culture from study participants with sign and symptom of vaginal abnormalities. Vulvovaginal candidiasis, bacterial vaginosis, and trichomoniasis are the most common cause of vaginitis of which vulvovaginal candidiasis is the second most common after bacterial vaginosis $[1,2]$. Nearly 5-10 million females seek gynecologic advice for vaginitis every year world-wide [3]. Many studies [3-8], have reported that three fourth (75\%) of women will experience an episode of vulvovaginal candidiasis in their lifetimes, $50 \%$ of these will experience at least a second episode, and $5-10 \%$ of all women experience recurrent vulvovaginal candidiasis i.e., $\geq 4$ episodes of vulvovaginal candidiasis per year.

Although the rate of vulvovaginal candidiasis is frequent, the reasons for its occurrence and recurrence are often unclear. Socio-demographic characteristics, use of antibiotics and oral contraceptives, diabetes mellitus, dietary practices, personal hygiene, sexual activity, and specific immunological defects have been identified as potential risk factors [3, 9-11]. However, the data supporting each of these factors are conflicting.

In most developing countries such as Ethiopia, vulvovaginal candidiasis is still received little attention since it is considered to be a trivial disease. However, vulvovaginal candidiasis has been identified as one of a global issues of concern due to its association with direct and indirect economic costs $[12,13]$, sexually transmitted infections, particularly HIV [14], and ascending genital tract infection [15].

Despite Candida albicans is the most common cause of vulvovaginal candidiasis, the frequency of vulvovaginal candidiasis caused by other Candida species, such as C. tropicalis, C. glabrata, and C. krusei is increasing, especially in HIV-infected women [16]. Yeast infections resistant to antifungal agents have been increasing and their frequency will likely continue to increase. Resistance to azoles antifungal therapy in C. albicans and non- albicans Candida species has become more common [17]. In Ethiopia, little is known regarding the distribution and the in vitro antifungal susceptibility profile of yeasts isolated from clinical samples including vaginal swabs. Poor laboratory set up and lack of expertise in the field can be incriminated as the major factors. In line with this, early and accurate identification of yeast pathogens and rapid antifungal susceptibility testing are the highest priority at least in cases of critical yeast infections. Against this background, the aim of this study was to identify and determine drug susceptibility profile of yeasts implicated in causing vulvovaginal candidiasis from patients attending at the Family Guidance Association of Ethiopian Addis Ababa model Clinic by employing the fully automated VITEK 2 compact system for the first time in Ethiopia. The VITEK 2 compact system is a fully automated and completely standardized microbiological system that performs both yeast identification and antifungal susceptibility testing simultaneously. A strong correlation between the VITEK 2 compact system in antifungal susceptibility testing and that of Clinical and Laboratory Standards Institute (CLSI) was demonstrated by Melhem et al. [18]. Apart from precise identification and susceptibility testing; shortened turnaround times, improved specimen handling, enhanced quality control, reproducibility and the ability to track results are further benefits of the system [19].

\section{Methods}

\section{Study design, period and area}

A cross sectional study was conducted from November 2015 to December 2016 at the Family Guidance Association of Ethiopian (FGAE) Addis Ababa model clinic. The association is the oldest and the largest non-government, not-for-profit organization with over 43 years of dedication in providing quality, broad ranging reproductive health services in Ethiopia complementing governmental efforts. It has 20 sexual and reproductive health care clinics across Ethiopia and 586 staff.

\section{Collection of socio-demographic, sexual behavior and reproductive health information}

Socio-demographic, sexual behavior, and reproductive health characteristics such as age, education, marital status, number of life time male sex partner, history of abortion, previous history of genital tract infection, frequency of vaginal bathing, and frequency of changing underwear were collected by face- to- face interviews using a structured questionnaire. Age groups of patients were classified following WHO guideline [20].

\section{Specimen collection, inoculation, transportation and incubation}

Prior to sample collection, patients with genital tract problem were clinically investigated by gynecologists on duty and signs and symptoms of vaginal abnormalities were recorded. Vaginal swabs were collected from study participants having different vaginal abnormalities such as vaginal discharge, itching, vulvar pruritus, irritation, pain during intercourse, and during urination using sterile rayon-tipped applicator stick swabs by experienced nurses. All vaginal swabs were then transferred without delay to the microbiology laboratory of the Department of Medical Laboratory Science, College of Health Sciences, Addis Ababa University. Each vaginal swab was inoculated onto to Sabouraud Dextrose Agar (SDA) supplemented with chloramphenicol (Oxoid, Basingstoke, UK) and incubated at $35-37^{\circ} \mathrm{C}$ for 18 to $24 \mathrm{~h}$ aerobically. Plates with no growth after $24 \mathrm{~h}$ were re-incubated for a 
further $24 \mathrm{~h}$. Preparation and performance evaluation of culture media were done as per the instruction of the manufacturer.

\section{Yeast identification and determination of antifungal susceptibility \\ Inoculum size determination}

Quality control yeast and pure cultures of yeast isolates were suspended in $3 \mathrm{ml}$ of sterile saline (aqueous 0.45 to $0.50 \% \mathrm{NaCl}, \mathrm{pH} 4.5$ to 7.0 ) in a $12 \times 75 \mathrm{~mm}$ clear plastic (polystyrene) test tube to achieve a turbidity equivalent to that of a McFarland 0.50 standard (range, 1.80-2.20), as measured by the DensiChek (bioMe'rieux) turbidity meter. These suspensions were used for the inoculation of YST-21343 identification cards while AST-YS01 cards were inoculated after yeast suspensions were further diluted following the instruction of the manufacture.

\section{Identification and determination of antimicrobial susceptibility}

Species identification and antimicrobial susceptibility testing of yeasts were determined by the automated VITEK 2 compact system (bioMérieux, France) using YST-21343 and AST-YSO1 cards. The system detects yeast growth and metabolic changes in the micro wells of thin plastic cards by using a fluorescence-based technology. In brief, identification cards were inoculated with quality control yeast and pure cultures of yeast isolate suspensions using an integrated vacuum apparatus. A test tube containing yeast suspension was placed into a special rack (cassette) and the identification card was placed in the neighboring slot while inserting the transfer tube into the corresponding suspension tube. The filled cassette was inserted manually into VITEK 2 compact reader-incubator module. After the vacuum was applied and air was re-introduced into the station, yeast suspension was forced through the transfer tube into micro-channels that fill all the test wells and inoculated cards were automatically sealed prior to loading into the carousel incubator. All card types were incubated automatically $35.5 \pm 1.0{ }^{\circ} \mathrm{C}$. Each card was removed from the carousel incubator once every $15 \mathrm{~min}$, transported to the optical system for reaction readings, and then returned to the incubator until the next read time. Data were collected at 15 -min intervals during the entire incubation period and final identification and antimicrobial testing (MIC and interpretation) results were obtained in approximately $18 \mathrm{~h}$ or less. A final identification of excellent, very good, good, acceptable, or low- discrimination was considered to be correct.

\section{Quality control}

Standard strains of C. albicans ATCC 10231 was used for quality control.

\section{Statistical analysis}

All data from the investigation were coded, doubleentered, and analyzed using SPSS version 20. Descriptive statistics and logistical regressions were used to estimate crude ratio with $95 \%$ confidence interval to the different variables. $P$-value $<0.05$ was considered significant.

\section{Ethical clearance}

All ethical considerations and obligations were duly addressed, and the study was conducted after the approval of the Department Research and Ethical Review Committee (DRERC) of the Department of Medical Laboratory Sciences, College of Health Sciences, and Addis Ababa University and the FGAE. Informed written consent was obtained from participants before data collection. Each respondent was given the right to refuse to take part in the study and to withdraw at any time during the study period. All information obtained from the study subjects were coded to maintain confidentially. When the participants were found to be positive for vulvovaginal candidiasis, they were informed by the hospital clinician and received proper treatment. An assent form was completed and signed by a family member and/or adult guardian for participants under the age of 18 years.

\section{Results}

In the present study we assessed yeast carriage associated with vaginal candidiasis symptoms. The overall prevalence of vulvovaginal candidiasis was $41.4 \%$. Subgroup prevalence of vulvovaginal candidiasis is presented in Table 1. Younger women, between 15 and 24 years had a somewhat lower prevalence $(35.1 \%)$ of vulvovaginal candidiasis, while in the 25 years and older group, the prevalence was between 40.0 and $44.8 \%$. The adjusted odds ratio showed that vulvovvaginitis was not significantly associated with age $(p=0.33)$.

The prevalence of vulvovaginal candidiasis varied with education and marital status. Women who are illiterate were more affected than those patients with primary school education and above. Similarly, vulvovaginal candidiasis was higher among divorced study subjects (52.6\%) compared to unmarried (41.5\%) or married (37.4\%) study subjects. Vulvovvaginitis also varied with selected reproductive health history characteristics. It was more in patients with previous genital tract infection $(52.6 \%)$ than in those patients with no previous genital tract infections (32.1\%). The adjusted odds ratio showed that vulvovaginal candidiasis was significantly associated with previous genital tract infection $(p=$ 0.004). The magnitude of infection was more or less the same in study subjects with history of abortion and with no history of abortion. The magnitude of vulvovaginitis was statistically significant with the number of life-time male sex partners $(p=.037)$ and number of male sex 
Table 1 Prevalence of vulvovaginal candidiasis (culture positive) by selected characteristics in relation to demographic and sexual and reproductive health (210)

\begin{tabular}{|c|c|c|c|c|c|c|c|c|c|}
\hline \multirow[t]{2}{*}{ Characteristics } & \multirow[t]{2}{*}{ Number } & \multicolumn{2}{|c|}{ Candidiasis } & \multirow[t]{2}{*}{ COR } & \multirow[t]{2}{*}{$95 \% \mathrm{Cl}$} & \multirow[t]{2}{*}{ P-value } & \multirow[t]{2}{*}{ AOR } & \multirow[t]{2}{*}{$95 \% \mathrm{Cl}$} & \multirow[t]{2}{*}{ P-value } \\
\hline & & Yes & No & & & & & & \\
\hline \multicolumn{10}{|l|}{ Age in years } \\
\hline $15-24$ & $54(25.7)$ & 19(35.1) & $34(62.9)$ & 1 & & & 1 & & \\
\hline $25-44$ & $116(55.2)$ & $52(44.8)$ & $65(56)$ & 0.490 & $0.244-0.986$ & 0.046 & 0.668 & $0.297-1.503$ & 0.330 \\
\hline $45-64$ & 40(19) & $16(40)$ & $24(60)$ & 0.348 & $0.147-0.822$ & 0.016 & 0.479 & $0.177-1.299$ & 0.148 \\
\hline Total & $210(100)$ & $87(41.4)$ & $123(58.5)$ & & & & & & \\
\hline \multicolumn{10}{|l|}{ Marital status } \\
\hline Un married & $65(30.9)$ & $27(41.5)$ & $38(58.4)$ & 1 & & & & & \\
\hline Married & $107(50,9)$ & $40(37.4)$ & $67(62.6)$ & 1.190 & $0.634-2.234$ & 0.588 & & & \\
\hline Divorced & $38(18)$ & $20(52.6)$ & 18(47.4) & 0.639 & $0.286-1.431$ & 0.277 & & & \\
\hline Total & $210(100)$ & $87(41.4)$ & $123(58.5)$ & & & & & & \\
\hline \multicolumn{10}{|l|}{ Education } \\
\hline Illiterate & $47(22.3)$ & $26(55.3)$ & $21(44.7)$ & 0.452 & $0.189-1.081$ & 0.074 & 0.297 & $0.106-2.831$ & 0.021 \\
\hline Primary school & $59(28)$ & $22(37.3)$ & $37(62.7)$ & 0.942 & $0.406-2.183$ & 0.889 & 1.096 & $0.407-2.950$ & 0.857 \\
\hline Secondary school & 65(30.9) & $25(38.5)$ & $40(61.5)$ & 0.896 & $0.393-2.041$ & 0.794 & 1.313 & $0.521-3.305$ & 0.563 \\
\hline College & 39(18.6) & 14(35.8) & $25(64.1)$ & 1 & & & 1 & & \\
\hline Total & $210(100)$ & $87(41.4)$ & $123(58.5)$ & & & & & & \\
\hline \multicolumn{10}{|c|}{ Number of life time male sex partner } \\
\hline $1-3$ & $136(64.7)$ & $48(35.2)$ & $88(64.7)$ & 1 & & & 1 & & \\
\hline$\geq 4$ & $74(35.2)$ & $39(52.7)$ & $35(47.2)$ & 2.043 & $1.148-3.635$ & 0.015 & 0.469 & $0.230-0.956$ & 0.037 \\
\hline Total & 210(100) & $87(41.4)$ & $123(58.5)$ & & & & & & \\
\hline \multicolumn{10}{|c|}{ Number of male sex partner in 12 month } \\
\hline 0 & $28(13.3)$ & $3(10.7)$ & 25(89.2) & 1 & & & 1 & & \\
\hline $1-2$ & $129(61.4)$ & $59(45.7)$ & $70(54.2)$ & 7.024 & $2.019-24.433$ & 0.002 & 16.784 & $4.043-69.684$ & 0.001 \\
\hline$\geq 3$ & $53(25.2)$ & 25(47.1) & $28(52.8)$ & 7.440 & $2.001-27.669$ & 0.003 & 14.988 & $3.454-65.030$ & 0.001 \\
\hline Total & $210(100)$ & $87(41.4)$ & $123(58.5)$ & & & & & & \\
\hline \multicolumn{10}{|l|}{ History of abortion } \\
\hline Yes & $52(24.7)$ & $21(40.3)$ & $31(59.6)$ & 1.059 & $0.560-2.004$ & 0.860 & & & \\
\hline No & 158(75.2) & $66(41.7)$ & $92(58.2)$ & 1 & & & & & \\
\hline Total & $210(100)$ & $87(41.4)$ & $123(58.5)$ & & & & & & \\
\hline \multicolumn{10}{|l|}{ Previous BV/GTI } \\
\hline Yes & $95(45.2)$ & $50(52.6)$ & $45(47.3)$ & 0.427 & $0.243-0.749$ & 0.003 & 0.368 & $0.187-1.724$ & 0.004 \\
\hline No & $115(54.7)$ & $37(32.1)$ & $78(67.8)$ & 1 & & & 1 & & \\
\hline Total & $210(100)$ & $87(41.4)$ & $123(58.5)$ & & & & & & \\
\hline \multicolumn{10}{|l|}{ Vaginal bathing /day } \\
\hline $1-3$ & $128(60.9)$ & $54(42.1)$ & $74(57.8)$ & 1 & & & & & \\
\hline$\geq 4$ & $82(39)$ & $33(40.2)$ & $49(59.7)$ & 1.084 & $0.617-1.904$ & 0.780 & & & \\
\hline Total & $210(100)$ & $87(41.4)$ & $123(58.5)$ & & & & & & \\
\hline \multicolumn{10}{|l|}{ No of pants used in a day } \\
\hline 1-2 Pant for one day & $92(43.8)$ & $31(33.6)$ & $61(66.3)$ & 1 & & & 1 & & \\
\hline One pant for 2-4 day & $118(56)$ & $56(47.4)$ & $62(52.5)$ & 0.563 & $0.320-0.988$ & 0.045 & 0.507 & $0.245-1.013$ & 0.045 \\
\hline Total & 210(100) & $87(41.4)$ & $123(58.5)$ & & & & & & \\
\hline
\end{tabular}


partners in 12 month $(p=0.001)$. The prevalence of vulvovaginal candidiasis was less than in those patients who changed underwear more frequently (two per day; $33.6 \%)$ than those who change their pants less frequently (one pant for 2-4 days; $47.4 \%$ ). Similarly, patients who bathed their vaginal region more frequently were less affected than that did not bath their vaginal area more frequently (prevalence rate $40.2 \%$ versus $42.1 \%$ ). As shown in Table 1, vulvovaginal candidiasis and personnel hygiene were not statistically associated.

Species distribution of Candida species is depicted in Table 2. A total of ten species of Candida were isolated from 210 women. C. albicans was the commonest isolate accounting for $58.6 \%$ of the total yeast isolate. The percentage of non-albicans Candida species (41.4\%) was less than that of C. albicans (58.6\%). Of the non-albicans Candida species, C. krusei was predominantly isolated (17.2\%), whereas C. lusitaniea and C. inconspicua were found to be the least prevalent isolates (1.2\%).

The overall drug susceptibility pattern of Candia species against the five antifungal drugs tested is shown in Table 3. The highest overall resistance rate of Candida species was observed against fluconazole (17.2\%), followed by flycytosine (5.7\%). All Candida isolates were $100 \%$ susceptible to voriconazole, caspofungin, and micafungin. As far as species specific antifungal resistance rates were concerned, $C$. albicans, the commonest isolate was $100 \%$ susceptible to all drugs tested except fluconazole and flycytosine with a resistance rate of $2 \%$ to each drugs. C. krusei, the second common isolate was 100 and $33.3 \%$ resistant against fluconazole and flycytosine, respectively.

\section{Discussion}

Information regarding the prevalence of vulvovaginal candidiasis in Ethiopia is not known. Regrettably, vulvovaginal candidiasis is not a reportable disease and the diseases is routinely diagnosed by sign and symptom

Table 2 Species distribution of Candida isolates from 210 patients with vulvovaginal candidiasis

\begin{tabular}{lll}
\hline Species of candida & Number of isolates & \% of the total isolates \\
\hline C. albicans & 51 & 58.6 \\
C. krusei & 15 & 17.2 \\
C. dubliniesis & 8 & 9.2 \\
C. glabrata & 3 & 3.4 \\
C. inconspicua & 1 & 1.2 \\
C. tropicalis & 2 & 2.3 \\
C. kefyr & 2 & 2.3 \\
C. guillieromondii & 2 & 2.3 \\
C. lusitaniae & 1 & 1.2 \\
C. parapsilosis & 2 & 2.3 \\
Total isolates 87 & & 100 \\
\hline
\end{tabular}

without the support of laboratory diagnosis. As the result, the spectrum of yeasts implicated in causing the disease and their drug susceptibility profile is not known in the country. The prevalence of vulvovaginal candidiasis varies from one study to another. It is the second most common infection of the vulvovaginal area of symptomatic women accounting for about $17 \%$ to 42 . $\%$ $[2,3,9]$. Although the prevalence rate of infection in our study $(41.4 \%)$ was within the reported range, it was slightly higher than the prevalence rates reported by Ahmed et al. [3] and Olowe et al. [9], but lower than the prevalence rate reported by ERylander et al. [21]. Differences in socio-demographic characteristics, immunestatus of patients [5], treating patients with broad spectrum antibiotics and immune suppressive drugs [22], and hormonal influences [23] have been identified as some of the factors for differences in the prevalence of the occurrence and/or recurrent vulvovaginal candidiasis among studies.

Age, level of education, and marital status as possible risk factors for vulvovaginitis were investigated in the present study. We did not find strong evidence about the associations between socio-demographic characteristics and the prevalence of vulvovaginal candidiasis. Among socio-demographic characteristics, age seems to be an important factor in the overall occurrence of vulvovaginal candidiasis. Out of 87 patients with vulvovaginal candidiasis, $71(81.6 \%)$ patients were in their 2nd to 4th decade of life. Our result was comparable with previous study. Sobel et al. [11] indicated that vulvovaginal candidiasis is infrequent at puberty (the first occurrence of menstruation), but its frequency increases towards the end of the second decade of life (10-19 years of age) reaching its peak in the third (20-29 years of age) and fourth (30-39 years of age) decade of life. Even though the crude odds ratio revealed that the association of age and vulvovaginal candidiasis was statistically significant the association was not statistically significant as far as the adjusted odds ratio was considered. This may indicate that the association was influenced by other variables.

The infection was more in women that were illiterate than in those patients with primary school education and above, and the association of vulvovaginal candidiasis and level of education was statistically significant $(p$ $=0.0 .021$ ). Improvement in personal hygiene and/or in economic status resulted from education may possibly explain the difference in the rate of infection between illiterates and those with better education. Our finding was consistent with the findings of Rathod et al. [24], but in contradiction with the conclusion reached by Vadav and Prakash [25]. Similarly, it was higher in divorced study subjects $(52.6 \%)$ than unmarried $(41.5 \%)$ or married (37.4\%) study subjects. The association of 
Table 3 In vitro antifungal susceptibility pattern of the isolates $(n=87)$

\begin{tabular}{|c|c|c|c|c|c|}
\hline Species & Antifungal agent & MIC range $(\mu \mathrm{g} / \mathrm{ml})$ & $\%$ susceptible of the isolates & $\%$ intermediate of the isolates & $\%$ resistant of the isolates \\
\hline \multirow[t]{5}{*}{ C. albicans (51) } & Fluconazole & $\leq 1$ & 98.0 & 2.0 & 0 \\
\hline & Voriconazole & $\leq 0.12$ & 100 & 0 & 0 \\
\hline & Caspofungin & $\leq 0.25-0.5$ & 100 & 0 & 0 \\
\hline & Micafungin & $\leq 0.06-\leq 0.25$ & 100 & 0 & 0 \\
\hline & Flycytosine & $\leq 1$ & 98.0 & 2.0 & 0 \\
\hline \multirow[t]{5}{*}{ C. krusei (15) } & Fluconazole & $2-\geq 64$ & 0 & 0 & 100 \\
\hline & Voriconazole & $\leq 0.12-\leq 0.25$ & 100 & 0 & 0 \\
\hline & Caspofungin & $\leq 0.25-0.5$ & 100 & 0 & 0 \\
\hline & Micafungin & $\leq 0.12-\leq 0.25$ & 100 & 0 & 0 \\
\hline & Flycytosine & $\leq 0.25-16$ & 66.7 & 0 & 33.3 \\
\hline \multirow[t]{5}{*}{ C. dubliniesis (8) } & Fluconazole & $\leq 1-32$ & 87.5 & 12.5 & 0 \\
\hline & Voriconazole & $\leq 0.12$ & 100 & 0 & 0 \\
\hline & Caspofungin & $\leq 0.25$ & 100 & 0 & 0 \\
\hline & Micafungin & $\leq-0.06-0.12$ & 100 & 0 & 0 \\
\hline & Flycytosine & $\leq 1-8$ & 87.5 & 12.5 & 0 \\
\hline \multirow[t]{5}{*}{ C. glabrata (3) } & Fluconazole & 4 & 100 & 0 & 0 \\
\hline & Voriconazole & $\leq 0-12$ & 100 & 0 & 0 \\
\hline & Caspofungin & $\leq 0.25$ & 100 & 0 & 0 \\
\hline & Micafungin & $\leq 0.06$ & 100 & 0 & 0 \\
\hline & Flycytosine & $\leq 1$ & 100 & 0 & 0 \\
\hline \multirow[t]{5}{*}{ C. tropicalis (2) } & Fluconazole & $\leq 1$ & 100 & 0 & 0 \\
\hline & Voriconazole & $\leq 0.12$ & 100 & 0 & 0 \\
\hline & Caspofungin & $\leq 0.25$ & 100 & 0 & 0 \\
\hline & Micafungin & $\leq 0.06$ & 100 & 0 & 0 \\
\hline & Flycytosine & $\leq 1$ & 100 & 0 & 0 \\
\hline \multirow[t]{5}{*}{ C. kefyr (2) } & Fluconazole & $\leq 1$ & 100 & 0 & 0 \\
\hline & Voriconazole & $\leq 0.12$ & 100 & 0 & 0 \\
\hline & Caspofungin & $\leq 0.25$ & 100 & 0 & 0 \\
\hline & Micafungin & 0.12 & 100 & 0 & 0 \\
\hline & Flycytosine & $\leq 1$ & 100 & 0 & 0 \\
\hline \multirow[t]{5}{*}{ C. guillieromondii (2) } & Fluconazole & 2 & 100 & 0 & 0 \\
\hline & Voriconazole & $\leq 0.12$ & 100 & 0 & 0 \\
\hline & Caspofungin & $\leq 0.5$ & 100 & 0 & 0 \\
\hline & Micafungin & 0.5 & 100 & 0 & 0 \\
\hline & Flycytosine & $\leq 1$ & 100 & 0 & 0 \\
\hline \multirow[t]{5}{*}{ C. parapsilosis (2) } & Fluconazole & $\leq 1$ & 100 & 0 & 0 \\
\hline & Voriconazole & $\leq 0.12$ & 100 & 0 & 0 \\
\hline & Caspofungin & $\leq 0.25$ & 100 & 0 & 0 \\
\hline & Micafungin & $\leq 0.25$ & 100 & 0 & 0 \\
\hline & Flycytosine & $\leq 1$ & 100 & 0 & 0 \\
\hline \multirow[t]{4}{*}{ C. Iusitaniae (1) } & Fluconazole & 2 & 100 & 0 & 0 \\
\hline & Voriconazole & $\leq 0.12$ & 100 & 0 & 0 \\
\hline & Caspofungin & $\leq 0.25$ & 100 & 0 & 0 \\
\hline & Micafungin & 0.5 & 100 & 0 & 0 \\
\hline
\end{tabular}


Table 3 In vitro antifungal susceptibility pattern of the isolates $(n=87)$ (Continued)

\begin{tabular}{|c|c|c|c|c|c|}
\hline Species & Antifungal agent & MIC range $(\mu \mathrm{g} / \mathrm{ml})$ & $\%$ susceptible of the isolates & $\%$ intermediate of the isolates & $\%$ resistant of the isolates \\
\hline & Flycytosine & $\leq 1$ & 100 & 0 & 0 \\
\hline \multirow[t]{5}{*}{ C. inconspicua (1) } & Fluconazole & $\leq 1$ & 100 & 0 & 0 \\
\hline & Voriconazole & $\leq 0.12$ & 100 & 0 & 0 \\
\hline & Caspofungin & $\leq 0.25$ & 100 & 0 & 0 \\
\hline & Micafungin & $\leq 0.06$ & 100 & 0 & 0 \\
\hline & Flycytosine & $\leq 1$ & 100 & 0 & 0 \\
\hline
\end{tabular}

vulvovaginitis with marital status was not statistically significant, but it was statistically associated with previous genital infection $(p=0.04)$. Our result was consistent with the findings of Rathod et al. [24].

Little attention has been given to reproductive health, behavioral factors, and personal hygiene as a risk factor for vulvovaginal candidiasis. In this study, the prevalence of vulvovaginal candidiasis by selected sexual behavior, reproductive health and personal hygiene was assessed. The results of the logistic regression analysis with the adjustment for potential confounders showed that vulvovaginal candidiasis was significantly associated with an increase in the number of life time male sex partner $(p$ $=0.037)$ and male sex partners in 12 months $(p=0.001)$. Our finding was not in line with other previous reports. Sobe et al. [11] indicated that number of years women had been with their sex partners is not associated with vulvovaginal candidiasis. Furthermore, the role of frequency of coitus as a risk factor to vaginitis remains controversial [26]. The study of Janković et al. [27], showed that vulvovaginal candidiasis was statistically associated with continual wearing of panty liners and use of vaginal tampons during menstruation, a finding which is inconsistent with our result $(p=0.054)$. The association of the infection with the frequency of vaginal bathing was not statistically significant $(p=.078)$.

Documented information regarding the spectrum and the in vitro antifungal susceptibility pattern of yeasts isolated from Ethiopian patients complaining of genital tract infection is not available. Among ten Candida species isolated in this study, the recovery rate for C. albicans was 51 (58.6\%), 15 (17.2\%) for C. krusei, 8 (9.2\%) for C. dubliniesis, 3 (3.46\%) for C. glabrata, 2 (2.3\%) for each of C. tropicalis, C. kefyr, C. parapsilosis, and C. guillieromondii and 1 for each of C. lusitaniae and C. iconpspicua. Our finding of $C$. albicans as the predominant species was consistent with similar earlier studies [11, 28]. Although numerous studies on the prevalence of different Candida species have led to the general agreement that $C$. albicans is the most commonly isolated species in patients with vulvovaginal candidiasis, there has been a growing trend of recovery of non-albicans Candida species. This is evident by the present study in which the isolation rate of non-albicans Candida species was $41.4 \%$. Comparatively, less recovery rates of non-albicans Candida species of $31.7 \%$ in Belgium [29] and $19.8 \%$ in the United States [28] have been reported. Also comparatively higher recovery rates of 53.1, 65.0, and $57.5 \%$ non-albicans Candida species have been reported in studies conducted in India [3], Egypt [30], and Iran [31], respectively.

Differences in the recovery rate among non-albicans Candida species were observed between our study and many earlier studies. A recovery rate $14.3 \%$ for $C$. glabrata, 5.9\% for C. parapsilosis and $8.0 \%$ for C. tropicalis was reported by Trama et al. [28]. The study of Sobel et al. [11], Nyirjesy [32], and Sobel et al. [33], revealed that C. glabrata was the predominant yeast among the non-albicans Candida species. The study of Bauters et al. [29] showed that C. glabrata as the most commonly isolated non-albicans Candida species (16.3\%), followed by, C. parapsilosis (8.9\%), C. humicola (1.6\%), C. krusei $(0.8 \%)$, and C. lusitaniae (0.8\%). Hasanvand et al. [34] demonstrated that C. albicans as the most commonly isolated species followed by C. glabrata, $C$. tropicalis, and C. parapsilosis. In contrast to these reports, C. krusei was the dominant non-albicans Candidia species in the present study accounting for $17.2 \%$ of the total isolates. The significance of this finding could be explained with caution that $C$. krusei may replace $C$. albicans under selective pressure of fluconazole, resulting in infections refractory to the current fluconazole based treatment in Ethiopia. Like other African countries, the present guideline of the Ethiopian Ministry of Health for the management of candidiasis includes fluconazole as a first choice drug and ketoconazole and $\mathrm{mi}$ conazole ointment as alternative antifungal agents [35, 36]. The widespread use of fluconazole or related azole antifungals to promote selection of resistant subpopulations by shifting colonization to more naturally resistant species especially C. krusei or C. glabrata was suggested by Alexander and Perfect [37]. Given that C. glabrata is naturally resistant to fluconazole, the rate of isolation of the yeast in the current study was lower than that of $C$. krusei. The spectrum and the relative frequencies of Candida species implicated in causing vulvovaginal candidiasis could probably vary from region to region and from country to country in the same region. Increased 
use of over-the-counter antifungal drugs inappropriately, frequently as a short, incomplete course of therapy, eliminating the more sensitive C. albicans and selecting for more azole-resistant non-albicans Candida species, prolonged therapy for recurrent candidiasis, and increased use of oral or topical azole agents-available as over-the counter have been suggested as a possible explanation for more frequent isolation of non-albicans Candida species from vulvovaginitis patients [38, 39].

The in vitro susceptibility testing of antifungal agents is becoming increasingly important because of the introduction of new antifungal agents and the recovery of clinical isolates that exhibit inherent or developed resistance to antifungal drugs. In this study, the drug susceptibility profile of all yeast isolates were tested against five antifungal drugs. Our study showed that fluconazole still appeared to be quite active against all isolates of C. albicans and non-albicans Candida species except for $C$. krusei. This indicated that there is no a continuing decline in the rate of fluconazole susceptibility, despite the continued widespread use of fluconazole both for therapy and for prevention for vulvovaginal candidiasis in Ethiopia. Our result was compatible with earlier studies $[40,41]$ that demonstrate the overall resistance in Candida spp to fluconazole and voriconazole has remained constant over a decade. Our result also invalidated, concerns about the rapid development of resistance to fluconazole after its introduction. In the present study, $C$. krusei which is reported to be intrinsically resistant to fluconazole [40] was $100 \%$ resistant to fluconazole. Therefore, our in vitro susceptibility results warrants clinicians working in health institutes with high proportion of cases of vulvovaginal candidiasis caused by C. krusei, which has high rates of resistance to fluconazole may consider the use of other alternative antifungal agents for treatment. The species was $100 \%$ susceptible to voriconazole. The voriconazole susceptibility of C. krusei vaginal isolates in the current study was consistent with other report [42]. We do not have an immediate explanation on the susceptibility difference between fluconazole and voriconazole against $C$. krusei as all azole antifungal drugs have a common mechanism of action, i.e., inhibition of ergosterol synthesis. [43]. Despite $C$. glabrata is reported to be naturally resistant species to fluconazole or related azole antifungals [37], all the three vaginal isolates of C. glabrata in the current study were susceptible to fluconazole and other azole antifungals. Our finding is more or less concurrent with the findings of Hasanvand et al. [34] in which out of 19 vaginal $C$. glabrata isolates only three isolates were resistant to fluconazole. Similarly, Richter et al. [39] documented that out of 112 isolates of C. glabrata only 67\% (51.8\% susceptible- dose- dependent, $15.2 \%$ resistant) was fluconazole non-susceptible. Discrepancies in the fluconazole susceptibility pattern in different studies should be verified by conducting further studies.

The in vitro susceptibility of all yeast isolates was $100 \%$ to both caspofungin and micafungin which block fungal cell wall synthesis by inhibiting the enzyme that synthesizes $\beta$-glucan. Similar result has been reported by Lyon et al. [40] and Pappas et al. [44]. In addition to this, the potency of both antifungal drugs was more or less the same against yeast isolates. Therefore, our study did not support disparity in potency (susceptibility) between the two echinocandins reported by Ostrosky-Zeichner et al. [45]. Ostrosky-Zeichner et al. [45], found that micafungin was 4 dilutions more potent than caspofungin. In contrast to azoles, echinocandins resistance does not seem to be a major concern, as global surveillance studies indicate that there has not been any significant epidemiological shift in the susceptibility of Candida spp. isolates to echinocandins [46]. Like-wise, almost all yeast isolates were susceptible to flucytosine with the exception of C. krusei which exhibited 33.3\% resistant rate. About $2 \%$ of C. albicans and $12.5 \%$ of C. dubliniesis were found out to be intermediate to flucytosine. Although, the prevalence of flucytosine resistance in yeast remains low, the speed at which yeast can develop resistance to flucytosine has driven clinicians to use the compound in combination with mainly amphotericin B [47].

\section{Conclusions}

High prevalence rate of vulvovaginal candidiasis and observation of a high prevalence rate of non-albicans Candida species in the present study warrants, the importance of conducting continuous epidemiological surveys to measure changes in species distribution from C. albicans to non-albicans Candida species in Ethiopia. Although, fluconazole still appeared to be active against all isolates of C. albicans and non-albicans Candida species high resistance rate of $C$. krusei against the drug may support a search for alternative antifungal drugs when treating vulvovaginal candidiasis caused by $C$. krusei.

\section{Acknowledgements \\ The authors would like to acknowledge the Family Guidance Association of Ethiopia Addis Ababa model Clinic for full cooperation during the study period. The authors are also indebted to the patients.}

\section{Availability of data and materials}

All the data are found in the manuscript and there are no supplementary files. The original data supporting this finding are available from the author and can be obtained at any time upon reasonable request.

\section{Authors' contributions}

YA, has participated in culture media preparation, identification of yeasts pathogens, in drafting the manuscript, have given final approval of the version to be published; analysis and interpretation of data, and agree to be accountable for all aspects of the work in ensuring that questions related to the accuracy or integrity of any part of the work are appropriately investigated and resolved. AB has participated in design, analysis and interpretation of data, 
yeast identification, write up of the manuscript, agree to be accountable for all aspects of the work in ensuring that questions related to the accuracy or integrity of any part of the work are appropriately investigated and resolved. Both authors have read and approved the final manuscript.

\section{Authors' information}

YA, is a medical laboratory technologist with Msc degree in microbiology, she has been working as a medical laboratory technologist for Fitche Hospital for many years.

$A B$ is an associate professor of microbiology and consultant health science specialist with a PhD degree. He has been working as a researcher and instructor offering courses to graduate students in the college of health sciences, Addis Ababa University for more than 24 years. He has published many original articles in peer-reviewed international journal.

\section{Ethics approval and consent to participate}

The study was conducted after it was ethically reviewed and approved by the Ethical Review board of the Department of Medical Laboratory Sciences (DRERC), School of Health Sciences, and Addis Ababa University. Written consents were also obtained from participants. Assent form was completed and signed by family member and/or adult guardian for participants under the age of 18 years.

\section{Competing interests}

The authors declare that they have no competing interests.

\section{Publisher's Note}

Springer Nature remains neutral with regard to jurisdictional claims in published maps and institutional affiliations.

\section{Author details}

${ }^{1}$ Department of Medical Laboratory Sciences, College of Health Sciences, Addis Ababa University, P.O. Box1176, Addis Ababa, Ethiopia. ${ }^{2}$ Department Clinical Laboratory, Fitche Hospital, P.O. Box 46, Oromia Administrative Region, Ethiopia.

\section{Received: 21 July 2017 Accepted: 8 June 2018}

Published online: 15 June 2018

\section{References}

1. Nyirjesy P, Sobel JD. Vulvovaginal candidiasis. Obstet Gynecol Clin N Am. 2003;30:671-84.

2. Anderson MR, Klink K, Cohrssen A. Evaluation of vaginal complaints. JAMA. 2004:291:1368-79.

3. Ahmad A, Khan AU. Prevalence of Candida species and potential risk factors for vulvovaginal candidiasis in Aligarh, India. Eur J Obstet Gynecol Reprod Biol. 2009:144:68-71.

4. Ilkit M, Guzel AB. The epidemiology, pathogenesis, and diagnosis of vulvovaginal candidosis: a mycological perspective. Crit Rev Microbiol. 2011. 37:250-61.

5. Sobel JD. Candida vulvovaginitis. Clin Obstet Gynecol. 1993;36:153.

6. Amouri I, Sellami H, Borji N, Abbes S, Sellami A, Cheikhrouhou F, et al. Epidemiological survey of vulvovaginal candidosis in Sfax, Tunisia. Mycoses. 2011:54:499-505.

7. Amouri I, Sellami H, Abbes S, Hadrich I, Mahfoudh N, Makni H, et al. Microsatellite analysis of Candida isolates from recurrent vulvovaginal candidiasis. J Med Microb. 2012;61:1091-6.

8. CDC. Sexually transmitted diseases treatment guidelines, 2010. MMWR. 2010;59(RR12):1-110

9. Olowe OA, Makanjuola OB, Olowe R, Adekanle DA. Prevalence of vulvovaginal candidiasis, trichomoniasis and bacterial vaginosis among pregnant women receiving antenatal care in Southwestern Nigeria. Eur J Microbiol Immunol. 2014;4:193-7.

10. Patel DA, Gillespie B, Sobel JD, Leaman D, Nyirjesy P, Weitz MV, et al. Risk factors for recurrent vulvovaginal candidiasis in women receiving maintenance antifungal therapy: results of a prospective cohort study. Am J Obst Gynecol. 2004;190:644-53.

11. Sobe JD, Faro S, Force RW, Foxman B, Ledger WJ, Nyirjesy PR, et al. Vulvovaginal candidiasis: epidemiologic, diagnostic, and therapeutic considerations. Am J Obst Gynecol. 1998;178:203-11.
12. Donder GG, Vereecken A, Bosmans E, Dekeersmaecker A, Salembier G, Spitz B. Definition of a type of abnormal vaginal flora that is distinct from bacterial vaginosis: aerobic vaginitis. Inter J Obstet Gynaecol. 2002;109:34-43.

13. Foxman B, Barlow R, d'Arcy H, Gillepsie B, Sobel JD. Candida vaginitis: selfreported incidence and associated costs. Sex Transm Dis. 2000;27:230-5.

14. Schaller M. Candida albicans-interactions with the mucosa and the immune system. J Dtsch Dermatol Ges. 2006;4:328-36.

15. Ferrer J. Vaginal candidosis: epidemiological and etiological factors. Int J Gynecol Obstet. 2000;71:S 21-7.

16. Sobel JD, Ohmit SE, Schuman P, Klein RS, Mayer K, Duerr A, et al. The evolution of Candida spp. and fluconazole susceptibility among oral and vaginal isolates recovered from human immunodeficiency virus (HIV)seropositive and at-risk HIV-seronegative women. J Infect Dis. 2001;183: 286-93.

17. Beltrame A, Matteelli A, Cristina A, Carvalho C, Saleri N, Casalini C, et al. Vaginal colonization with Candida spp. in human immunodeficiency virusinfected women: a cohort study. Int J STD AIDS. 2006:17:260-6.

18. Melhem MSC, Bertoletti A, Lucca HRL, Silva RBO, Meneghin FA, Szeszs MW. Use of the VITEK 2 system to identify and test the antifungal susceptibility of clinically relevant yeast species. Braz J Microbiol. 2013;44:1257-66.

19. Donay JL, Mathieu D, Fernandes P, Pregermain C, Bruel P, Wargnier A, et al. Evaluation of the automated phoenix system for potential routine use in the clinical microbiology laboratory. J Clin Microbiol. 2004;42:1542-6.

20. WHO. Provisional Guidelines on Standard International Age Classifications: Statistical Papers, Series M, vol. 74. New York: United Nations; 1982. p. 4-11.

21. ERylander E, Berglund A-L, Krassny C, Petrini B. Vulvovaginal candida in a young sexually active population: prevalence and association with orogenital sex and frequent pain at intercourse. Sex Transm Infect. 2004;80: $54-7$

22. Xu J, Schwartz K, Bartoces M, Joseph M, Severson R, Sobel JD. Effect of antibiotics on vulvovaginal candidiasis: a Metro Net study. J Am Board Fam Med. 2008:21:261-8.

23. Spinillo A, Capuzzo E, Nicola S, Baltaro F, Ferrari A, Monaco A. The impact of oral contraception on vulvovaginal candidiasis. Contraception. 1995;51: 293-7.

24. Rathod SD, Klausner JD, Krupp K, Reingold AL, Adhivanan P. Epidemiologic Features of Vulvovaginal Candidiasis among Reproductive-Age Women in India. Infect Dis ObstGynecol. 2012;2012:859071, 8 pages. https://doi.org/10. 1155/2012/859071.

25. Yadav K, Prakash S. Prevalence of vulvovaginal candidiasis in pregnancy. Glob J Med Med Sci. 2016;4:108-16.

26. Spinillo A, Carrata L, Pizzolia G. Reccurent volvovaginal candidiasis: result of a cohort study of sexually transmitted transmission and intestinal reservoir. J Repord Med. 1992:37:343-7.

27. Janković $\mathrm{S}$, Bojović $\mathrm{D}$, Vukadinović $\mathrm{D}$, Daglar $\mathrm{E}$, Janković $\mathrm{M}$, Laudanović $\mathrm{D}$, et al. Risk factors for recurrent vulvovaginal candidiasis. Vojnosanit Pregl. 2010;67:819-24.

28. Ttrama JP, Adelson ME, Raphaelli I, Stemmer SM, Mmordechai E. Detection of Candida species in vaginal samples in a clinical laboratory setting. Infect Dis Obstet Gynecol. 2005;13(2):63-7.

29. Bauters TGM, Dhont MA, Temmerman MI, Nelis HJ. Prevalence of vulvovaginal candidiasis and susceptibility to fluconazole in women. Am J Obstet Gynecol. 2002:187:569-74.

30. Haleim MMA, El-Feky EAM, Sayed A, Ismail DK, Sayed AM, Abdella RMA. Provence of non albicans species associated with vulvovaginal candidiasis in Egyptian women. Int J Adv Int Health Sci. 2015;12:304-13.

31. Hedayati MT, Taheri Z, Galinimorhadam T, Aghili SR, Cherati JY, Mosayebi E. Isolation of different species of candida in patients with vulvovaginal candidiasis from Sari, Iran. Jundishapur J Microbial. 2015;8:e15992. https:// doi.org/10.5812/jjm .8(4)2015.1599.

32. Nyirjesy P, Seeney SM, Grody MHT, Jordan CA, Buckley HR. Chronic fungal vaginitis: the value of cultures. Am J Obstet Gynecol. 1995;173:820-3.

33. Sobel JD, Wiesenfeld HC, Martens M, Danna P, Hooton TH, Rompalo A, et al Maintenance fluconazole therapy for recurrent vulvovaginal candidiasis. $\mathrm{N}$ Engl J Med. 2004;351:876-83.

34. Hasanvand S, Qomi HA, Kord M, Didehdar M. Molecular epidemiology and in vitro antifungal susceptibility of Candida isolates from women with vulvovaginal candidiasis in northern cities of Khuzestan Province. Iran Jundishapur J Microbiol. 2017;10(8):12804. https://doi.org/10.5812/jjm.12804.

35. Guidelines for Management of Opportunistic Infections and Antiretroviral Treatment in Adolescents and Adults in Ethiopia. Federal HIV/AIDS 
Prevention and Control. Addis Ababa: Office Federal Ministry of Health; 2007.

36. Ministry of Health. Standard Treatment Guideline. Addis Ababa: Drug Administration and Control Authority, Ministry of Health; 2004.

37. Alexander $B D$, Perfect JR. Antifungal resistance trends towards the year 2000: implications for therapy and new approaches. Drugs. 1997;54:657-78.

38. Safdar A, Chaturvedi V, Cross EW, Park S, Bernard EM, Armstrong D, et al. Prospective study of Candida species in patients at a comprehensive cancer center. Antimicrob Agents Chemother. 2001;45:2129-33.

39. Richter SS, Rudolph P, Galask RP, Shawn A, Messer SA, Richard J, et al. Antifungal susceptibilities of Candida species causing vulvovaginitis and epidemiology of recurrent cases. J Clin Microbiol. 2005;43:2155-62.

40. Lyon GM, Karatela S, Sunay S, Adiri Y. Antifungal susceptibility testing of Candida isolates from the Candida surveillance study. J Clin Microbiol. 2010; 48:1270-5.

41. Pfaller MD, Diekema D, Gibbs V, Newell J, Meis I, Gould W, et al. Results from the ARTEMIS DISK global antifungal surveillance study, 1997 to 2005: an 8.5-year analysis of susceptibilities of Candida species and other yeast species to fluconazole and voriconazole determined by CLSI 30 standardized disk diffusion testing. J Clin Microbiol. 2007;45:1735-45.

42. Diekema DJ, Messer SA, Brueggemann AB, Coffman SL, Doern GV, Herwaldt $L A$, et al. Epidemiology of candidemia: 3 -year results from the emerging infections and the epidemiology of lowa organisms study. J Clin Microbiol. 2002;40:1298-302.

43. Rex J, Stevens D. Systemic antifungal agents. In: Mandell G, Bennett J, Dolin $R$, editors. Principles and practice of infectious diseases, vol. 1. 6th ed. Philadelphia: Elsevier; 2005. p. 501-11.

44. Pappas PC, Rotstein R, Betts M, Nucci D, Talwar J, De Waele J, et al. Micafungin versus caspofungin for treatment of candidemia and other forms of invasive candidiasis. Clin Infect Dis. 2007;45:883-93.

45. Ostrosky-Zeichne LA, Lashof MO, Kullberg BJ, Rex JH. Voriconazole salvage treatment of invasive candidiasis. Eur J Clin Microbiol Infect Dis. 2003;22: $651-5$.

46. Munro CA. Fungal echinocandin resistance. F1000 Biol Rep. 2010;2:66.

47. Kanafani ZA, Perfect JR. Antimicrobial resistance: resistance to antifungal agents: mechanisms and clinical impact. Clin Infec Dis. 2008;46:120-8.

\section{Ready to submit your research? Choose BMC and benefit from:}

- fast, convenient online submission

- thorough peer review by experienced researchers in your field

- rapid publication on acceptance

- support for research data, including large and complex data types

- gold Open Access which fosters wider collaboration and increased citations

- maximum visibility for your research: over $100 \mathrm{M}$ website views per year

At BMC, research is always in progress.

Learn more biomedcentral.com/submissions 